\title{
Spatial scales of surface wind observations and analysed wind fields over the North Atlantic Ocean
}

\author{
K. Bumke \\ Institut für Meereskunde, Düsternbrooker Weg 20, D 24105 Kiel, Germany
}

Received 6 September 1993; revised and accepted 21 December 1993

\begin{abstract}
It is well known that spatial scales of oceanic eddies are smaller than scales of atmospheric eddies. Since the spectral distribution of kinetic energy of atmospheric eddies may influence the properties of wind driven oceanic eddies, an excellent resolution of small scale variability of wind fields used as input fields of coupled models of atmosphere and ocean is necessary. Analysis of spatial scales of atmospheric fields is done in terms of spectral energy densities. These are determined in two different ways: directly from objectively analysed fields or by using spatial correlation functions of direct observations averaged for $20 \mathrm{~km} \times 20 \mathrm{~km}$ boxes. In the spectral range of wavelengths of less than $1000 \mathrm{~km}$ spectral energy densities of analysed fields have lost about 15 to $50 \%$ of the variance compared to direct observations. A considerable part of this loss of the variance depends on smoothing done by interpolation schemes themselves.

Concerning problems of air-sea interaction care should be taken also to avoid that systematic errors of analysed wind fields lead to systematic errors in turbulent exchange. It is shown that high observed wind speeds are considerably underestimated in analysed fields of numerical models of weather prediction.
\end{abstract}

\section{Introduction}

Detailed knowledge of surface wind fields is necessary for the improvement of coupled models of ocean and atmosphere. Irregulary distributed observations therefore necessitate the interpolation on a regular gridpoint field. Since interpolation schemes tend to smooth spatial scales, a loss of variance of analysed fields compared to the variability of original observations is to be expected. Turbulent momentum flux $\tau$ is commonly taken to be proportional to the square of the average windspeed $U$. But since the absolute value of $\tau$ is approximately proportional to the average of the squared windspeed, $\tau$ should be better defined as follows (e.g. Hasse, 1968):

$$
\tau=\varrho C_{\mathrm{D}} \overline{U^{2}}=\varrho C_{\mathrm{D}}\left(\bar{U}^{2}+\overline{U^{\prime 2}}\right)
$$

It is obvious that a loss of variance will lead to a reduction of turbulent exchange. In a similar manner systematic errors of $U$ lead to errors in the estimation of turbulent fluxes. Therefore an interpolation scheme is optimal with regard to air-sea interaction if spatial scales are conserved during analysis and the analysed fields are nonbiased.

To estimate the suitability of analysed fields to drive coupled models of ocean and atmosphere a 
good knowledge about the small scale variability of direct observations is necessary. Earlier studies have been done by Willebrand (1978), but have been restricted to observations of weatherships. In this work observations of merchant ships are used to get information about spatial scales included in direct observations. This allows an examination down to much smaller scales.

\section{Data base}

Synoptic observations of international voluntary observing ships and coastal stations, which have been transmitted via GTS (Global Telecommunication System), have been made available by the DWD (Deutscher Wetterdienst) for the region of the North Atlantic Ocean. Observations include air pressure, humidity, wind speed and direction, air and water temperature. To avoid any influence of orographic effects, wind and temperature observations of land and island stations have been excluded in this examination. Data are available for periods from May 1982April 1985 and October 1991-August 1992, 12 GMT. Wind speeds have been reduced from an average height of $20 \mathrm{~m}$ (Cardone et al., 1990) to $10 \mathrm{~m}$ height for neutral stability.

The locations of observations are given in $0.1^{\circ}$ latitude/longitude. Pairs of observations both having the same locations have not been taken into consideration since these are likely double storage of one observation. Therefore the shortest distance between two observations ranges from about $5-16 \mathrm{~km}$ with a standard deviation of \pm 4.9 to $\pm 6.3 \mathrm{~km}$ assuming a homogeneous distribution of observations. According to the accuracy of position data the correlation functions have been averaged over boxes of $20 \mathrm{~km} \times 20 \mathrm{~km}$.

The synoptic observations have been analysed by the IfM (Institut für Meereskunde) for the region of the North Atlantic Ocean. Parameters of analysed fields are air pressure, wind speed and direction, air and water temperature. The IfM analysis scheme has been developed to calculate true surface wind fields with a high spatial resolution specially for the use in air sea interac- tion studies. Resolution is limited by the availability of synoptic observations. A $2^{\circ} \times 2^{\circ}$ grid was used. This resolution corresponds to a total number of about 1000 grid points for the analysed field, which agrees well to the number of items of information from direct observations. Air pressure, wind speed and wind direction is counted as one item of information each. The analysis scheme bases on the polynomial method (e.g. Panofsky, 1949) and fits a second order pressure surface both to observations of surface pressure and to observations of wind. Using a stability dependent boundary layer parametrisation, geostrophic equilibrium of wind and pressure field is assumed:

$p^{\prime}=a_{00}+a_{10} x+a_{20} x^{2}+a_{11} x y+a_{01} y+a_{02} y^{2}$

$u_{\mathrm{g}}^{\prime}=-\frac{a_{01}+a_{11} x+2 a_{02} y}{f \rho}$

$v_{\mathrm{g}}^{\prime}=\frac{a_{10}+a_{11} y+2 a_{20} x}{f \rho}$

Here $x, y$ are distances between points of observation and the grid point in the east and north direction. A prime denotes an estimated variable.

Since observations may include errors, redundant information is used and the polynominal is solved by minimizing the sum $S$

$$
\begin{aligned}
S= & (1-W) \sum_{k=1}^{n} C^{2}\left(p-p^{\prime}\right)^{2} \\
& +W \sum_{i=1}^{m} C^{2}\left[\left(u-u^{\prime}\right)^{2}+\left(v-v^{\prime}\right)^{2}\right]
\end{aligned}
$$

using wind and pressure observations simultaneously to estimate the coefficients $a_{i k}$. Here $p, u$ and $v$ are the pressure and surface wind components obtained from ship observations.

The weight $W$ serves to optimize the influence of wind and pressure information, we use $W=0.7$. The weights $C$ have been introduced to provide decreasing weight for observations at increasing distance to the grid point. For this purpose a 
Cressman function (Cressman, 1959) was selected. In order to achieve high spatial resolution, at each grid point we use only those observations nearest to grid point under consideration that together yield a minimum number of twelve items of information. The radius enclosing these observations is taken as characterizing the resolution and estimates the equivalent filter half width of the distance weighting function. Our analysis scheme provides a mean resolution of $220 \mathrm{~km}$ equivalent filter half width (Bumke and Hasse, 1989).

A first run of this analysis scheme has been used to detect probably wrong observations, which may be included in the GTS dataset.

Analysed fields of the IfM are available for the same period as the synoptic observations.

Grid point fields of the "Europamodell" of the DWD are available for the period from October 1991-August 1992, 12 GMT. They comprise the air pressure and wind components in $10 \mathrm{~m}$ height. The grid point distance varies only slightly and is about $50 \mathrm{~km}$ for the whole area. Since the grid point distance is much smaller than that of the IfM gridpoint field, a better spatial resolution of small scale variability could be expected.

Two different grid point fields are available from the ECMWF (European Centre for Medium Range Weather Forecasts): analysed fields of the wind components for a period from September 1984-December 1984, 12 GMT, and first guess fields of windstress for a period from January 1985-April 1985, 12 GMT. Spatial resolution is $1.875^{\circ}$ grid point distance. The examination of characteristics of these ECMWF fields is of interest since the FGGE data set is still in use in air sea interaction studies.

The ECMWF model and the Europamodell of the DWD, are spectral models using the method of Optimum Interpolation (Shaw et al., 1984). This demands the introduction of an empirical correlation function, which may limit spatial resolution of analysed fields. Until May 1985 the ECMWF has used a Gauss function with a half width of about $580-1000 \mathrm{~km}$. Further smoothing may be done by the data selection scheme during assimilation. The ECMWF has used for this purpose "analysis boxes" of horizontal dimensions of about $1000 \mathrm{~km}$ square. More details are given in Lönnberg and Shaw, 1987.

The Europamodell uses modified correlation functions of the Globalmodell of the DWD. The Globalmodell itself is the present ECMWF model with a different spatial resolution and orography. Details of the analysis scheme are given in Majewski (1993).

\section{Observation errors}

As mentioned above the observations include observational errors, which can be considered as stochastic. Numerical analysis schemes ideally average over this kind of error in a way that an analysed field does not show any systematic error. Calculating variances of observations the variance of the observation error does not vanish.

Thus it is necessary to estimate the observation error. This is achieved by calculating variances between simultaneous observation from two or more ships at short distances. Before calculating the observation errors, obviously wrong observations have been eliminated by a first run of the IfM analysis scheme. As mentioned above pairs of observations both having the same locations have not been taken into consideration. The following observation errors given in terms of the rms-deviation for all dates from May 1982-April 1985 are calculated for pairs of observations having a distance of less than $20 \mathrm{~km}$ :

air pressure: $1.0 \mathrm{hPa}$

wind speed: $1.5 \mathrm{~ms}^{-1}$

Since observation error does not increase up to distances until $40 \mathrm{~km}$ it is understood that the local small scale synoptic variability of the meteorological parameters cannot be separated from observation errors. The rms-deviation of observations of wind speed is in the same order than calculated under optimal conditions for the research vessels during GATE to $1.3 \mathrm{~ms}^{-1}$ (Godshall et al., 1976). The rms-deviation of the air pressure is much higher than the value of 0.4 $\mathrm{hPa}$ as estimated during GATE (Godshall et al., 1976) but of the same order as given by Arpe (1985) as a typical observation error of ship synops. 


\section{Analysis error}

No systematic error is expected since an analysis scheme averages over the observation errors. Indeed systematic deviations between observations and the IfM grid point fields are neglegible small. Deviations have been calculated by interpolating the grid point values linearely on the location of the observation. The resulting rms-deviations between observations and IfM gridpoint fields are $1.8 \mathrm{~ms}^{-1}$ for wind speed and $1.2 \mathrm{hPa}$ for air pressure for all dates from 1984, 12 GMT. For all dates from October 1991-August 1992, 12 GMT, the rms-deviations are $1.9 \mathrm{~ms}^{-1}$ for wind speed and 1.1 hpa for air pressure. Neither in 1984 nor in the period from October 1991-August 1992 could there be found any bias in wind speed. The rms-deviations are nearly of the same order than the observation errors. Assuming that the observation error and the analysis error of the IfM analysis scheme are stochastic, the analysis error of the IfM gridpoint fields is $\leqslant 1.3 \mathrm{~ms}^{-1}$ for wind speed and $\leqslant 0.7 \mathrm{hPa}$ for sea level air pressure. The estimated wind speeds by the IfM analysis scheme show no systematic deviations as a function of observed wind speed. This is shown in Fig. 1 which represents the analysed wind speed as a function of observed wind speed and vice versa. Assuming the same error for observations and analysed wind speeds, the averaged linear regression line

$U_{\text {IfM }}=0.13 \mathrm{~ms}^{-1}+1.02 U_{\mathrm{OBS}}$

(Stolte, pers. commun.) agrees well with the $45^{\circ}$ line. The correlation coefficient is high, about 0.91 .

Using the same set of observations Fig. 2 shows the analysed wind speeds of the Europamodell of the DWD as a function of observations and vice versa. The differences at high observed wind speeds are much bigger than for the analysed fields of the IfM. The averaged linear regression line (Stolte, 1993) is given by

$U_{\mathrm{DWD}}=0.66 \mathrm{~ms}^{-1}+0.82 U_{\mathrm{OBS}}$

assuming again same errors for observations and analysis. The correlation coefficient is only about 0.82. Eq. (7) indicates that the Europamodell



Fig. 1. Analysed wind speed of the IfM plotted against ship observations of wind speed. Wind speeds are for $10 \mathrm{~m}$ height. dots: averaged over intervals of observed wind speed. squares: averaged over intervals of analysed wind speed. full line: $45^{\circ}$ line.

underestimates high wind speeds considerably. Fig. 3 shows the differences of analysed to observed wind speeds as a function of observed air

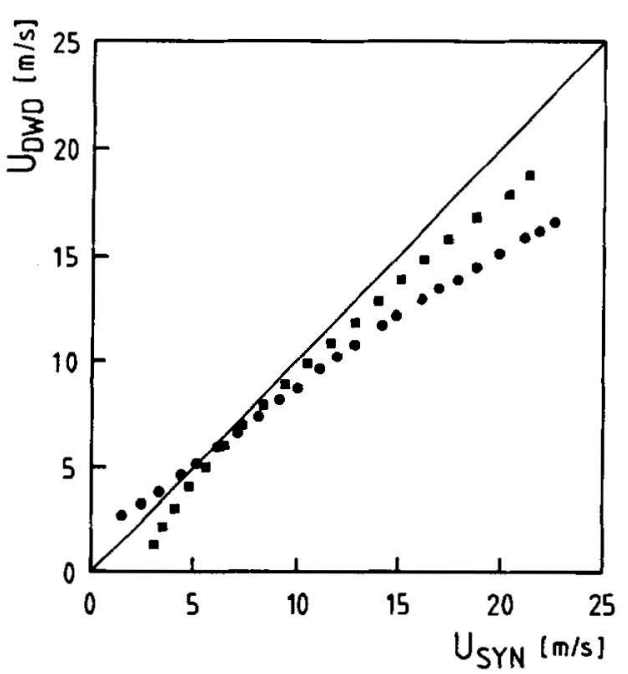

Fig. 2. Analysed wind speed of the Europamodell of the Deutscher Wetterdienst plotted against ship observations of wind speed. Wind speeds are for $10 \mathrm{~m}$ height. dots: averaged over intervals of observed wind speed. squares: averaged over intervals of analysed wind speed. full line: $45^{\circ}$ line. 


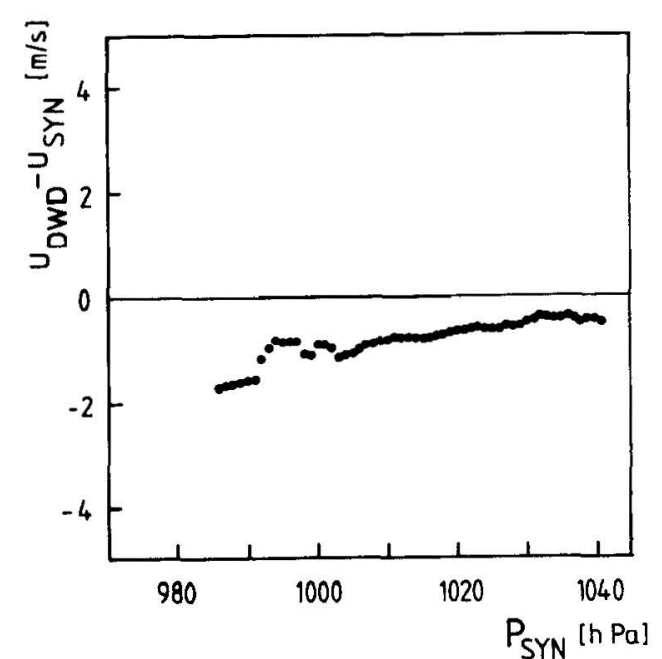

Fig. 3. Difference of the analysed wind speed of the Europamodell of the Deutscher Wetterdienst minus observed wind speed as a function of ship observations of sea level air pressure.

pressure. The plot shows an underestimation of analysed windspeed of the Europamodell for low air pressures. Since low air pressure is equivalent to cyclonic activity and therefore to high wind speeds, this result indicates an underestimation of high wind speeds too. One could expect a tendency to underestimate lows and highs resulting in a smaller pressure gradient and therefore reduced wind speeds.

Moreover the agreement of grid point fields of air pressure of the Europamodell compared to observed air pressure is rather good as indicated by Fig. 4. The differences to the IfM analysis of pressure is only marginal. The correlation coefficient is about 0.99 .

Another possible reason for the underestimation of high wind speeds is the use of an insufficient boundary layer parametrisation. Indeed the Charnock constant used in the Europamodell of the DWD has been too high by about a factor of two (Majewski, 1993). Meanwhile the Charnock constant of the Europamodell has been adjusted accordingly.

Eliminating the systematic error of analysed wind speeds of the Europamodell by using Eq. (7), the analysis error of the analysed wind speed of the Europamodell is about $1.3 \mathrm{~ms}^{-1}$. Thus it is

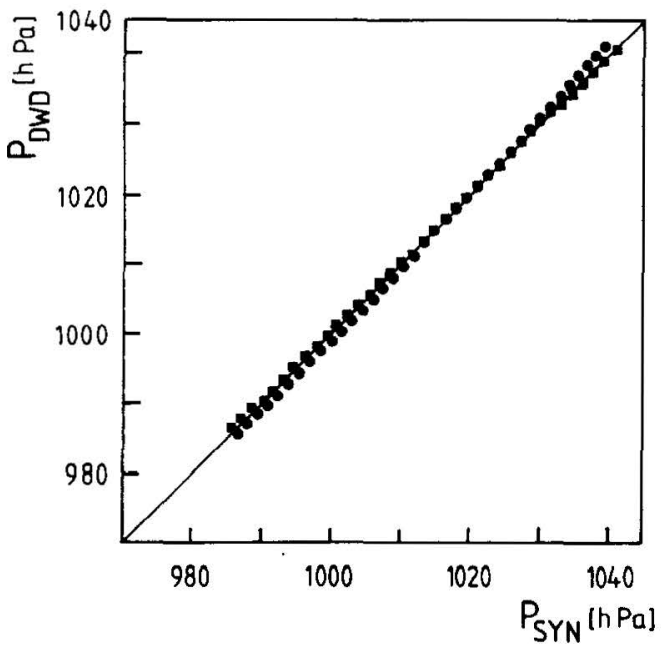

Fig. 4. Analysed surface pressure of the Europamodell of the Deutscher Wetterdienst plotted against ship observations of pressure. dots: averaged over intervals of pressure observations. squares: averaged over intervals of analysed pressure. full line: $45^{\circ}$ line.

of the same order than for analysed wind speeds of the IfM. This proves that the wind fields of the DWD advantageously could be used for air-sea interaction studies.

A similar investigation has been made with $1.825^{\circ} \times 1.825^{\circ}$ data of ECMWF.

Systematic differences between the ECMWF analyses of wind speed and IfM analyses are again of the order 1 or $2 \mathrm{~ms}^{-1}$. The comparison of zonal averaged wind speeds of the IfM and ECMWF analyses for four months of 1984 are given in Fig. 5. Such differences in zonal averaged wind speeds up to about $20 \%$ lead to esti-

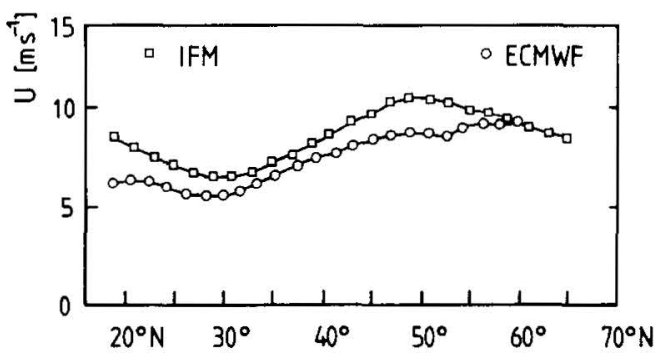

Fig. 5. Zonal averaged wind speed $U$ of analysed grid point fields of the IfM Kiel (squares) and the ECMWF (dots) as a function of latitude, averaged over the period from September until December 1984, 12.00 GMT. 
mated fluxes of momentum, which differ by about a factor of two between IfM and ECMWF analysis.

Using drag coefficients given by Isemer (1987), to calculate windstress from analysed wind fields of IfM and compare these with first guess fields of ECMWF wind stress for a period from January-April 1985, no systematic differences in stress have been detected. Since the numerical model of the ECMWF has not changed at the end of 1984 the boundary layer parametrisation apparently compensates for the bias in wind speed.

\section{Spatial scales}

In the following spatial scales of the wind field will be considered in terms of spectral energy densities. Spectral energy densities can be calculated via a Fourier Transformation, if series of input values are given in equal distances of time or space.

To calculate spectral energy densities from ship observations the main difficulty rests in the fact that observations are rather sparse and locations of observations are changing with time.

One possibility to solve the problem is that the autocorrelation function $C_{11}(r)$ and the energy spectrum $E_{11}(k)$ are a transformation pair (e.g. Bath, 1974) according to:

$C_{11}(r)=\frac{1}{2 \pi} \int_{-\infty}^{\infty} E_{11}(k) \mathrm{e}^{i k r} \mathrm{~d} k$

$E_{11}(k)=\int_{-\infty}^{\infty} C_{11}(r) e^{-i k r} \mathrm{~d} r$

If the correlation function is known it is possible to estimate the spectral energy densities for the direct observations.

To obtain correlation functions we make use of the fact that the correlation function can be calculated as a function of distance only for homogeneous fields (e.g. Wickert, 1971). A proof of the homogeneity of fields is possible, since for all dates analysed fields of the IfM are available. Differences between correlation functions of analysed fields, calculated with and without the

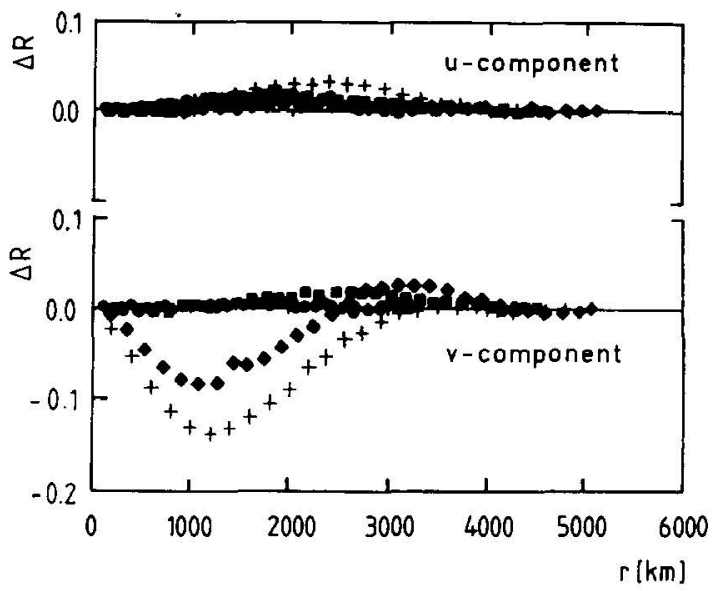

Fig. 6. Differences of zonal autocorrelation function of wind components $u$ and $v$, calculated with and without the assumption of homogenity, $\Delta R$ as a function of the distance $r$ of grid points and of latitude. diamonds: $19^{\circ} \mathrm{N}$ to $29^{\circ} \mathrm{N}$. crosses: $31^{\circ} \mathrm{N}$ to $39^{\circ} \mathrm{N}$. squares: $41^{\circ} \mathrm{N}$ to $49^{\circ} \mathrm{N}$. dots: $51^{\circ} \mathrm{N}$ to $65^{\circ} \mathrm{N}$.

assumption of homogeneity, should vanish, if fields are homogeneous. Fig. 6 indicates that latitudes north of $40^{\circ} \mathrm{N}$ can be regarded as homogeneous in zonal direction. Thus zonal autocorrelation functions of direct observations were estimated in this regions.

The number of observations is sufficient to obtain the correlation function of direct observations averaged for intervals of $20 \mathrm{~km}$. The calculated zonal correlation functions and confidence intervals for the zonal and meridional wind components $u$ and $v$ are shown in the Fig. 7 in comparison to estimated correlation functions of the IfM gridpoint fields. The agreement is good, nevertheless the higher correlation coefficients at small distances $r$ indicate the smoothing of small scale variability by the IfM analysis scheme.

In the present article spatial spectral energy densities will be shown for wavelengths ranging from about $6000 \mathrm{~km}$ down to about $40 \mathrm{~km}$. This range of wavelength can be divided roughly into two parts following Golitsyn (in: Gifford, 1988):

- Wavelengths from about $6000 \mathrm{~km}$ down to $1000 \mathrm{~km}$ : transfer of squared vorticity to smaller scales leads to spectra proportional to $k^{-3}$, where $k$ is the wave number.

- Wavelengths less than about $1000 \mathrm{~km}$ : trans- 


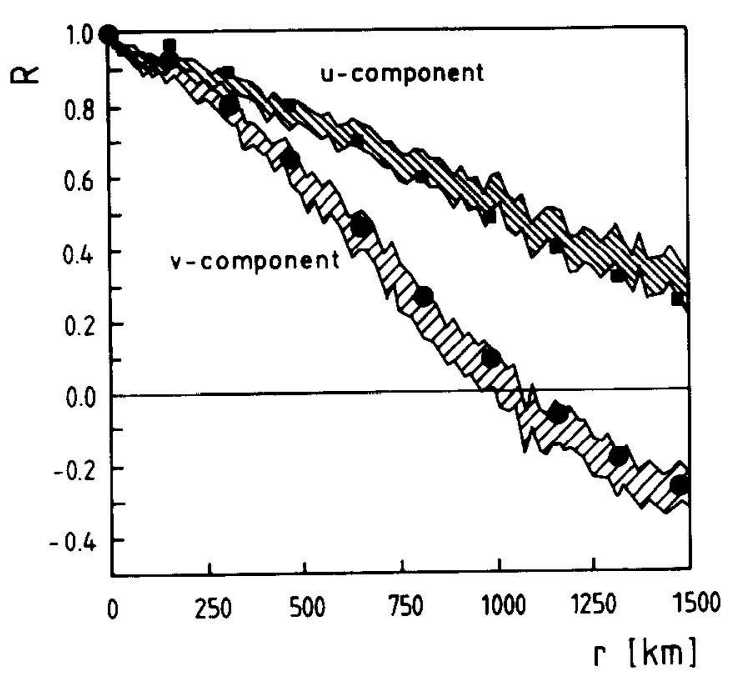

Fig. 7. Zonal correlation function $R$ of the $u$ - and $v$-component of wind as a function of distance $r$. May 1982-April 1985, 12.00 GMT. shaded areas: $95 \%$ confidence interval of correlation function of direct observations. squares, dots: averaged correlation function of IfM grid point fields.

fer of kinetic energy to smaller scales resulting in the well known proportionality to $k^{-5 / 3}$.

The spectral energy densities of analysed fields have been calculated directly by a Fourier Transformation while spectral energy densities of direct observations have been derived from the correlation function. The results are shown in the Figs. 8-10 for direct observations and different kinds of grid point fields.

Note that spectral energy densities of grid point

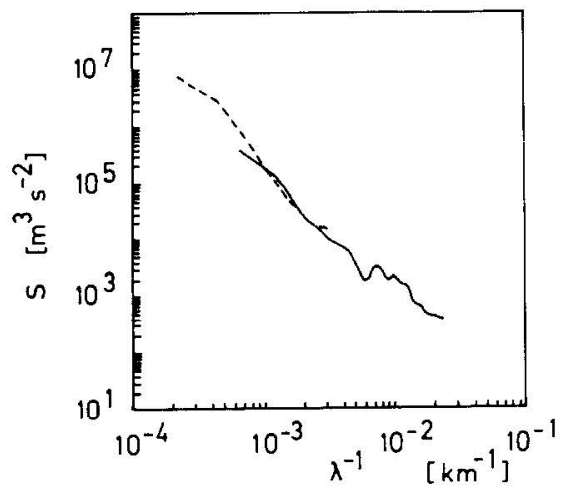

Fig. 8. Zonal spectral energy densities $S$ in $\mathrm{m}^{3} \mathrm{~s}^{-2}$ of wind speed as a function of inverse wavelength $\lambda$ in $\mathrm{km}^{-1}$. May 1982 until April $1985,12.00 \mathrm{GMT}, 40^{\circ} \mathrm{N}$ to $50^{\circ} \mathrm{N}$. dashed line: analysed grid point field of IfM Kiel. full line: observations.

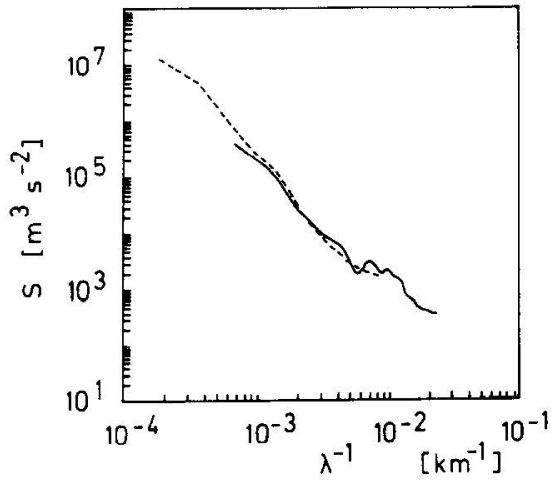

Fig. 9. Spectral energy densities $S$ in $\mathrm{m}^{3} \mathrm{~s}^{-2}$ of wind speed as a function of inverse wavelength $\lambda$ in $\mathrm{km}^{-1}$ calculated along an axis from southwest-northeast for a period from October 1991-August 1992, 12.00 GMT. For comparison: Zonal spectral energy density of direct observations, May 1982-April $1985,12.00 \mathrm{GMT}, 40^{\circ} \mathrm{N}$ to $50^{\circ} \mathrm{N}$. dashed line: analysed grid point fields of the Europamodell of the DWD. full line: observations.

fields of the Europamodell of the DWD have been calculated in a direction from southwest to northeast while all other spectral densities have been calculated in zonal direction. This has been done to avoid interpolation of the grid point field of the Europamodell.

The spectral energy densities of direct observations and of the grid point fields of the IfM and Europamodell follow the theoritical expected slope proportional to $k^{-3}$ and to $k^{-5 / 3}$ at smaller wavelengths well.

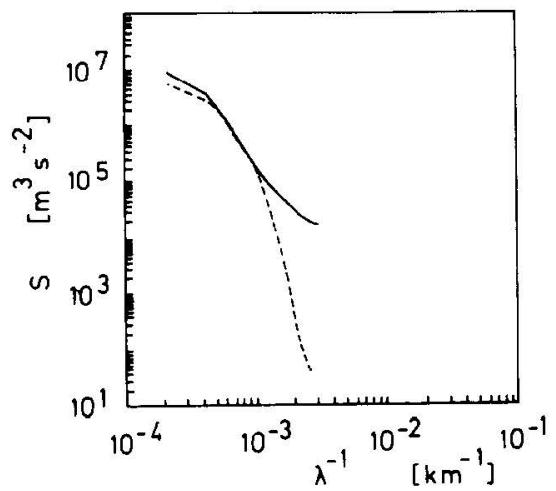

Fig. 10. Zonal spectral energy densities $S$ in $\mathrm{m}^{3} \mathrm{~s}^{-2}$ of wind speed as a function of inverse wavelength $\lambda$ in $\mathrm{km}^{-1}$. September 1984-December $1984,12.00 \mathrm{GMT}, 40^{\circ} \mathrm{N}$ to $50^{\circ} \mathrm{N}$. dashed line: analysed grid point field of the ECMWF. full line: analysed grid point fields of the IfM. 
This agrees well with results of Nastrom and Gage (1985) who calculated spectral energy densities from air plane measurements. Julian et al. (1970) found a proportionality of spectral energy densities from $k^{-2.7}$ to $k^{-3}$ for wavelengths from $3500 \mathrm{~km}$ down to $1500 \mathrm{~km}$. This is in a good agreement with spectral energy densities of the IfM grid point fields showing in the same range of wavelengths a proportionality to $k^{-2.9}$.

For smaller wavelengths Freilich and Chelton (1986) have estimated a proportionality of spectral energy densities to $k^{-2.2}$ applying to wavelengths down to $200 \mathrm{~km}$ for wind fields derived from Seasat measurements. In the same range of wavelengths spectral energy densities of the IfM grid point fields show a proportionality of about $k^{-2.15}$.

Spectral energy densities of the ECMWF are proportional to about $k^{-6}$ at smaller wavelengths. This indicates considerable reduction of small scale energy. Similar results have been published by McVeigh et al. (1987) estimating spectral energy densities of the curl of windstress of ECMWF analyses.

Spectral energy densities of first guess fields of wind stress of the ECMWF (Fig. 11) indicate again smoothing of small scale variations in comparison to corresponding spectral energy densities of windstress calculated from the IfM grid point fields by a bulk parametrisation.

The smoothing of small scale variance can be

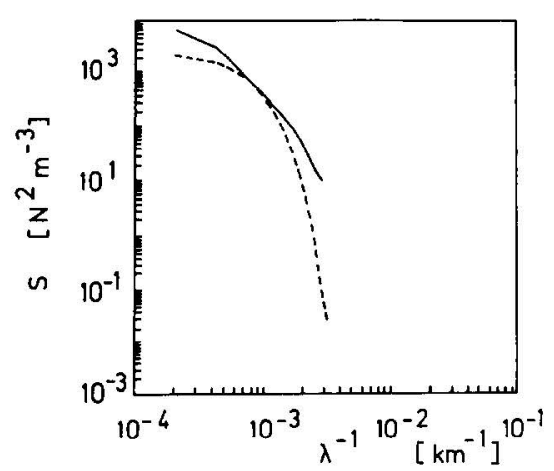

Fig. 11. Zonal spectral energy densities $S$ in $\mathrm{N}^{2} \mathrm{~m}^{-3}$ of wind stress as a function of inverse wavelength $\lambda$ in $\mathrm{km}^{-1}$. January 1985 -April $1985,12.00 \mathrm{GMT}, 40^{\circ} \mathrm{N}$ to $50^{\circ} \mathrm{N}$. dashed line: first guess grid point field of the ECMWF. full line: analysed field of the IfM using drag coefficients of Isemer (1987). normalized in terms of the variance of direct observations for wavelengths of less than 1000 $\mathrm{km}$. To take into account that the input data set of ECMWF grid point fields may differ from observational data set spectral energy densities are normalized at $1000 \mathrm{~km}$ wavelength on the same value for observations and ECMWF grid point fields. Since spectral energy densities of the Europamodell and of direct observations have been calculated in different directions and periods, spectral energy densities of both have been normalized at a wavelength of $1000 \mathrm{~km}$ on the same value too.

The loss of variance expressed in terms of the variance of direct observations for wavelengths of less than $1000 \mathrm{~km}$ is:

$-32 \%$ for analyses of the IfM

- 50\% for analyses of the ECMWF

$-15 \%$ for analyses of the DWD

About half of the loss of the variance of the IfM grid point fields is caused by the grid point distance of $2^{\circ}$ yielding to a Nyquist Wavelength of about $250-400 \mathrm{~km}$ depending on latitude. Therefore the remaining lost of variance depends on the analysis scheme. Since the grid point distance of the analysed fields of the ECMWF is only marginal better, the considerable smoothing of small scale variability is mainly caused by the interpolation scheme of the data acquisition cycle.

\section{Conclusions}

It has been shown that analysed wind fields may have biases of the order of up to $20 \%$ of observed wind speeds. These biases would lead to systematic errors in determination in air sea interactions.

Additionally analysed fields show a smoothing of small scale variance which at wavelengths of less than $1000 \mathrm{~km}$ may reach up to about $50 \%$ of the small scale variability of direct observations. This would lead to considerable errors in air-sea interaction too.

A comparison of the results for ECMWF grid point fields from the period $1984 / 85$ and the Europamodell of the DWD from 1991/92 is an 
example for the progress in numerical weather prediction. Since the ECMWF model and its spatial resolution has improved in recent years one might expect an improvement of the resolution of small scale variance too. As an example nowadays a Bessel function is used as correlation function (Lönnberg and Shaw, 1987) instead of a Gauss function. Data acquisition of both models of numerical weather prediction show an underestimation of high wind speeds compared to observed wind speeds.

The IfM grid points fields do not show a bias compared to observations. Therefore this answers implicitly the query why it was advantageous to use a special procedure analysing wind fields at sea though numerical models of weather forecast produce regularly such fields.

In case of the Europamodell our examinations resulted in a correction of the Charnock constant used in the model in April 1993. It has to be checked that this adjustment has eliminated the systematic error that has been found in the past. Because of high resolution the grid point fields of the Europamodell of the DWD will be very useful for the use in air-sea interaction studies.

\section{Acknowledgement}

This work was supported by the Deutsche Forschungsgemeinschaft. It is part of research of the Sonderforschungsbereich 133, "Warmwassersphäre des Atlantik", at the Universität Kiel. The synoptic data, analysed fields of the Europamodell and the ECMWF fields were kindly provided by the Deutscher Wetterdienst and the European Centre for Medium Range Weather Forecasts. I appreciate the comments of the reviewer.

\section{References}

Arpe, K., 1985. Meteorological Data: Kind, Distribution, Accuracy and Representativeness. Meteorol. Training Course, Lecture Note, 2.1, ECMWF.

Bath, M., 1974. Spectral Analysis in Geophysics. Developments in Solid Earth Geophysics, 7. Elsevier, Amsterdam, $563 \mathrm{pp}$.
Bumke, K. and Hasse, L., 1989. An analysis scheme for determination of true surface winds at sea from ship synoptic wind and pressure observation. Boundary-Layer Meteorol., 47: 295-308.

Cardone, V.J., Greenwood, J.G. and Cane, M.-A., 1990. On trends in historical wind data. J. Climate, 3: 113-127.

Cressman, G.P., 1959. An operational objective analysis system. Mon. Weather Rev., 87: 367-374.

Freilich, M.H. and Chelton, D.B., 1986. Wavenumber spectra of pacific winds measured by the Seasat scatterometer. J. Phys. Oceanogr., 16: 741-757.

Gifford, E.A., 1988. A similarity theory of the tropospheric turbulence energy spectrum. J. Atm. Sci., 45(8): 1370-1379.

Godshall, F.A., Seguin, W.R. and Sabol, P., 1976. GATE convection subprogram data center: Analysis of ship surface meteorological data obtained during gate intercomparison periods. NOAA Techn. Rep. EDS, 17: 1-73.

Hasse, L., 1968. Zur Bestimmung der vertikalen Transporte von Impuls und fühlbarer Wärme in der wassernahen Luftschicht über See. Hamb. Geophys. Einzelschriften, 11. Cram, de Gruyter, Hamburg, 70 pp.

Isemer, H.-J., 1987. Optimierte Parametrisierungen der klimatologischen Energie- und Impulsflüsse an der Oberfläche des Nordatlantik. Ber. Inst. Meereskunde, 160, 184 pp.

Julian, P.R., Washington, W.M., Hembrie, L. and Ridley, C., 1970. On the spectral distribution of large scale kinetic energy. J. Atm. Sci., 27: 376-387.

Lönnberg, P. and Shaw, D., 1987. ECMWF data assimilation - Scientific documentation. ECMWF Res. Manual 1, 10/87, 2nd Revised Edition.

Majewski, D., 1993. Short description of the Europa-Modell (EM) and Deutschland-Modell (DM) of the Deutscher Wetterdienst (DWD) as at April 1993. Deutscher Wetterdienst Offenbach, Forschungsabteilung, 59 pp.

McVeigh, J.P., Barnier, B. and LeProvost, C., 1987. Spectral and empirical orthogonal function analysis of four years of European center for medium range weather forecast wind stress curl over the North Atlantic Ocean. J. Geophys. Res., 92(C12): 13,141-13,152.

Nastrom, G.D. and Gage, K.S., 1985. A climatology of atmospheric wavenumber spectra of wind and temperature observed by commercial aircraft. J. Atm. Sci., 42(9): 950 960.

Panofsky, H.A., 1949. Objective weather map analysis. J. Meteorol., 6: 386-392.

Shaw, D.B., Lönnberg, P. and Hollingsworth, A.H., 1984. The 1984 revision of the ECMWF analysis scheme. ECMWF Techn. Mem., 92, 96 pp.

Stolte, S., 1993. Überprüfung der vom Europamodell analysierten Wind- und Druckfelder auf dem Nordatlantik. Diplomarbeit, Inst. Meereskunde Kiel, 52 pp.

Wickert, S., 1971. Simple statistical methods in the study of meteorological fields. In: Statistical Methods and Instrumentation in Geophysics. Teknol. Forlag, Oslo, pp. 67-69.

Willebrand, J., 1978. Temporal and spatial scales of the wind field over the North Pacific and North Atlantic. J. Phys. Oceanogr., 8(6): 1080-1094. 